\title{
Reading lists - time for a reality check? An investigation into the use of reading lists as a pedagogical tool to support the development of information skills amongst Foundation Degree students
}

\author{
Gillian Siddall, Hannah Rose
}

\begin{abstract}
This article presents the results of an action research project exploring the use and value of reading lists for Foundation Degree students. The focus of the research was to look at the potential of reading lists to act as a pedagogical tool to support information skills development. The research methodology included focus groups with students, interviews with academic staff and reading list analysis. It was found that reading lists were being used by students to identify and find resources for their academic studies. Qualitative data from students and staff illustrate how reading lists are being used and the gaps between student and staff expectations of them. The article provides recommendations on how reading lists can be utilised to help students to develop their information skills.
\end{abstract}

\section{Introduction}

Within the fields of Education and Health there is a need for assistant and support practitioners who have fundamental work-related skills, knowledge and experience (Cavendish, 2013; Harvey, 2009) which can be developed through Foundation Degree (FD) programmes (Pratt, 2008). The University of Northampton offers Foundation Degree courses in Education and Health that often attract students with practical experience rather than traditional academic

\section{Authors}

Gillian Siddall (BA (Hons), MA, PGCTHE, MCLIP, FHEA) is the Academic Librarian for the School of Health, University of Northampton.

Email: gillian.siddall@ northampton.ac.uk

Hannah Rose (BA (Hons) MA PGCTHE FHEA, University Teaching Fellow) is the Academic Librarian for the School of Education, University of Northampton. 
backgrounds, such as teaching assistants who study the Foundation Degree in Learning and Teaching. Whilst fulfilling the requirements of the national widening participation agenda (Laing et al., 2005; University of Northampton, 2013; House of Commons Public Accounts Committee, 2009), these students present different challenges in learning and skills development. They often demonstrate anxiety around the requirements of academic study and lack confidence in their ability to complete and pass assessments (Bowl, 2001). The authors regularly work with FD students in information skills sessions organised by tutors, as well as one-to-one support. The key skills of accessing, retrieving, using and evaluating information are central to these sessions (SCONUL, 2011). This research will focus on one way in which students may be enabled to improve these skills and their confidence - through the use of enhanced reading lists.

The authors are Academic Librarians and therefore engage with reading lists in a number of different ways. For example, reading lists are used in collection development, informing purchase decisions. Therefore reading lists are regularly checked for updates and new editions. Academic Librarians also encounter reading lists when supporting students to find resources for their assignments. In both cases the authors come across mistakes and inaccuracies in reading lists, which hinder students from finding tutor recommended resources.

Furthermore, through conversations with students and their tutors, the authors have become aware that students have difficulty using the current course reading lists. Students either read everything or nothing and they find it difficult to identify which texts are most appropriate for their level and skills. It is clear that the existing lists are not meeting the students' needs (Thomson et al., 2003/2004).

The authors therefore wished to explore the value of enhanced reading lists and specifically, how these can be used as a teaching and learning tool to support students to develop the information skills needed for academic study in Higher Education (HE). Not only will this work have a beneficial impact on Northampton FD students' ability to access, retrieve and use information, but also it would fill a gap in the literature which has not so far addressed the pedagogical impact of reading lists on information skills.

\section{Research aims and objectives}

The aim of this research is to investigate the use of reading lists as a pedagogical tool to support the development of information skills of Foundation Degree students in Health and Education.

The research objectives are:

- To understand how Foundation Degree students use and respond to academic reading lists;

- To explore academic staff perceptions of the use and value of reading lists; 
- To investigate whether the use of annotated reading lists can support the development of FD students' information skills.

\section{Literature review}

As Academic Librarians for the Schools of Education and Health at the University of Northampton, the authors teach students at a range of academic levels. There is one Foundation Degree course within the School of Education, the Foundation Degree in Learning and Teaching (FDLT). Students studying a Foundation Degree within Education are already working as support staff in schools and wish to further their career within the Education sector. Similarly, within the School of Health, students are often employed as assistant practitioners, such as Dental Nurses or Health Care Assistants. A large number of the FD students will not have taken the traditional academic route into Higher Education (Laing et al., 2005; Herrera et al., 2014).

Therefore, the authors looked at how students who were not typical in Higher Education (HE) (i.e. those who did not enter university directly from another educational institution) faced the expectations of academic study at University (Penketh and Goddard, 2008). This literature review will look at the potential barriers to learning in $\mathrm{HE}$ and the value of reading lists before evaluating the debate of scaffolding versus spoon-feeding. The review will conclude by describing the information literacy (IL) model that influenced the construction of this action research project.

FD students are less likely to have experience of HE and therefore lack the confidence to study at this level and fear failure (Morris, 2009; Fenge, 2011; Penketh and Goddard, 2008). "The imposter phenomenon" and lack of selfconfidence can be debilitating for learners in HE who do not have a support mechanism (Thurgate et al., 2007, 220; McDevitt, 2006; James, 2002). Support mechanisms can come in many forms, from an academic tutor who helps students prepare for $\mathrm{HE}$, to a reading list that includes literature at the right level for the students (Stokes and Martin, 2008; Smith, 2008). A key support mechanism these students use is study skills support - a team of academic tutors who can help them to develop these skills, such as academic writing. Some FD students have little confidence and self-esteem in terms of the ability to study in HE, which leads to "academic anxiety" (Russell, 2009, 59). The varied educational history of FD students also has implications for their expectations of study at HE.

There is a disparity between the students' and staff expectations of HE and what is involved in academic study (Smith, 2008; Stark and Warne, 1999). In her work Bowl (2003) illustrates that these learners are not fully conversant with academic norms and conventions.

The external doors of academia may have been opened, but the internal doors which might reveal the expectations of the academy remained closed...

(Bowl, 2003, 139) 
More generally, it is recognised that there is a discrepancy between students' expectations of university and the university's definition of a student (Winter and Dismore, 2010). These "mismatched expectations" are illustrated throughout the literature as students express uncertainty about what and how much to read (Maher and Mitchell, 2010). Our student respondents certainly expressed desires for more open and direct communication between lecturers and students about what reading to do and how much was really necessary for their course of study (Stokes and Martin, 2008). With little or no experience of academic study in recent years, FD students can find it difficult to understand the expectations of their tutors, which can result in low confidence and anxiety around academic work. Students in these courses fail to understand basic academic procedures (Morris, 2009; Russell, 2009). Bowl (2001) documents how students blame themselves for their misunderstandings of the rules of academia. This theory is further evidenced by the cultural mismatch highlighted in the work of Penketh and Goddard (2008). This struggle for survival in the alien world of academia is exacerbated by staff failing to appreciate or to understand where students are coming from and how they feel when confronted with the academic world of HE (Chipperfield, 2013; Bowl, 2001).

Issues around low confidence and self-esteem have been witnessed within information skills teaching sessions. The authors suspected that the students' lack of confidence and subsequent anxiety (often compounded by their lack of experience with ICT and electronic resources) might be getting in the way of their learning and in particular, on their ability to find and evaluate information. Some studies have reported similar scenarios where adult learners' low self-confidence and feelings of anxiety have impacted on their learning and subsequent use of information resources (Chipperfield, 2013; Collins and Veal, 2004; Craig and Corrall, 2007; Moon, 2005). The transition to study in HE can be an emotional one, as evidenced in the paper by Martin and Stokes (2006) exploring students' experience of reading lists:

...frustration was also frequently expressed over recommended texts not being easily understandable or readable.

(Martin and Stokes, 2006, 34).

There is a need to explore what strategies could be implemented to help to ease the transition to academic study and to support FD students to develop their confidence and information skills (Fenge, 2011). It is not just a case of the student adapting to $\mathrm{HE}$, there needs to be change on the part of the University to create positive educational experiences (Chipperfield, 2013; Penketh and Goddard, 2008). Universities must develop inclusive pedagogic practices that take into account diverse educational histories, needs and interests of students (Piscioneri and Hlavac, 2013). Bamber and Tett (2000) argue there is a need to provide sustained support to these non-traditional students, through pedagogical change. Sympathetic teaching approaches to ease first year students' transition to HE would benefit all and would improve the student experience more generally (Winter and Dismore, 2010). HE institutions can take a more proactive approach 
to adapt to the student rather than students adapting to the HE environment (Morris, 2009). This could be achieved through explicit and shared dialogues about what is expected in HE (Maher and Mitchell, 2010; Herrera et al., 2014).

\subsection{Reading lists as a pedagogical tool}

One possible strategy that could be explored is the use of reading lists as a pedagogical tool to support the development of information skills. During the literature search it was clear that whilst some literature covers reading lists, this tends to focus on the content and structure rather than their value as a pedagogical tool (Thomson et al., 2003/2004; Stokes and Martin, 2008).

Some studies have highlighted the benefit of signposting students to different sources of information in terms of level and style of writing, so that they can select the most appropriate source for them. Reading lists have been recognised as a method of communication from tutors, to students and librarians (Brewerton, 2014, 79). However, the use of reading lists for this purpose requires an active approach to the design and management of reading lists (Miller, 1999; Stokes and Martin, 2008). Anecdotal evidence from our experience in checking reading lists for collection management purposes has highlighted that some tutors do not view their reading lists as living documents that evolve every year. They have instead become static records of the tutor's own reading experience (Stokes and Martin, 2008).

\subsection{Spoon-feeding or scaffolding?}

It is possible that the use of annotated reading lists may be criticised for "oversupporting" or "spoon-feeding" students (Smith, 2008). Some argue that if students do not have to search for their own material it will inhibit their development towards becoming autonomous information users (Stokes and Martin, 2008). However, it is clear from the literature that there is a difference between spoon-feeding students' information and providing them with scaffolding (e.g. annotated reading lists) to support them to develop the skills to access, retrieve and use information (Piscioneri and Hlavac, 2013). Van Der Stuyf (2002, 2) described the principle of "scaffolding" as follows:

An important aspect of scaffolding instruction is that the scaffolds are temporary. As the learner's abilities increase the scaffolding provided by the more knowledgeable other is progressively withdrawn. Finally the learner is able to complete the task or master the concepts independently.

(Van Der Stuyf, 2002, 2)

This notion of scaffolding informed the development of annotated reading lists where the students received clear signposting to a range of resources for different levels and abilities, provided by a "more knowledgeable other". In this case, the more knowledgeable other was the Academic Librarian and tutor working together to combine their experience to offer support to the students through signposting and rich annotation on the reading list. For the purposes of this project 
the academic librarians and tutors collaborated to explore whether annotated lists could be valuable. This signposting was "progressively withdrawn" as students advanced throughout their course of study and developed the skills and confidence to identify and locate resources of their own volition (Van Der Stuyf, 2002, 2; McKenzie, 1999). This approach further developed the award-winning work by one of the authors on the scaffolding approach to information skills development (Lumsden et al., 2010).

\subsection{Information Literacy model}

The authors used SCONUL's Seven Pillars (SCONUL, 2011) as the basis of information literacy models they would use to evaluate the research. Specifically, this involved examining how reading lists could help students to "construct strategies for locating information" (SCONUL, 2011). During the reading list analysis, the authors looked at how academics "organise, apply and communicate" information to students (SCONUL, 2011). In the newer "core model" of IL SCONUL (2011) illustrates that individuals develop along the pillars at different times. A good reading list will help students identify search terms and understand the scope of the information landscape. It would not necessarily address all seven pillars, but it would give a student a solid foundation from which to learn and develop further (SCONUL, 2011).

The SCONUL Seven pillars model highlights a number of skills that an RL can help students to develop. Principally a good reading list can help students to identify a range of information and scope of current knowledge in the subject area (SCONUL, 2011). The clear structure and bibliographic information on a reading list can be used to demonstrate how to manage and use information ethically. Therefore even at its most basic level a reading list can model three key pillars to students. An annotated reading list could go further to illustrate how to evaluate information - looking at different types of resources, perhaps selecting a key chapter to read rather than just listing the book. If a reading list was updated regularly to include newer information it could also highlight how to 'gather' information, aiding students in locating and accessing information in different mediums (SCONUL, 2011).

After considering the implicit barriers faced by FD students entering an HE institution it is clear that reading lists could be a useful mechanism to scaffold students to develop the IL skills for academic success.

\section{Methodology}

This research was based upon the theories of action research, aiming to improve professional practice of the authors (Gray, 2009). It was recognised that action research would result in overlap during the various stages of the process (Gray, 2009). The benefit of the iterative process of action research allowed the researchers to reflect and adapt during the project, encouraging a cyclical process of action and review (see Figure 1). The research was based on a concurrent triangulation design to explore the value of reading lists as a pedagogical tool using qualitative interviews and focus groups and quantitative reading list analysis 
(Robson, 2011). The triangulation of quantitative and qualitative techniques enabled the research to explore:

...the [topic] from different perspectives and to understand [it] in a more rounded and complete fashion than would be the case had the data been drawn from just one method.

(Denscombe, 2003, 132; Cohen, et al., 2013, 197)

Through the use of multiple methods to investigate reading lists the research highlights the diversity of views explored and therefore the completeness of the review (Bryman, 2012).

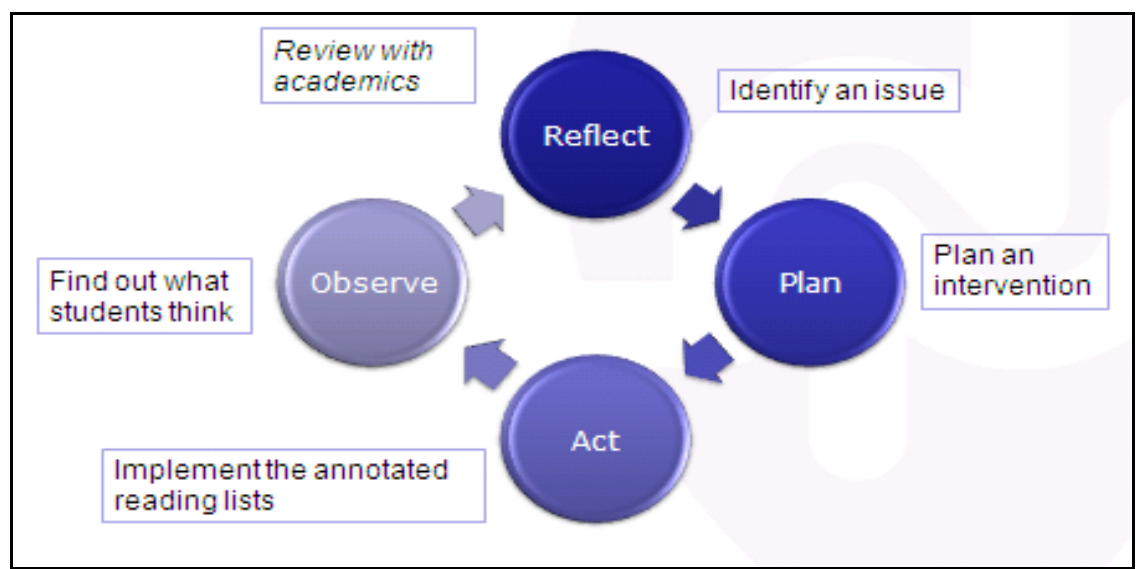

Figure 1: Action research cycle for reading list research

The research involved level four and five FD students studying within the Schools of Education and Health at the University of Northampton. Level 4 Foundation Degree students are studying at the equivalent level of the first year of a UK Bachelor's degree, Level 5 students are in the equivalent of the second year. A Foundation Degree consists of two years' study and students are awarded their degree when they complete Level 5. For the purposes of this research students are referred to simply by their academic year [Year 1 or Year 2] and not by subject, in order to ensure the anonymity of participants. Students and academic staff gave voluntary informed consent and were provided with full anonymity when they took part in the focus groups and interviews (Bell, 2010; Denscombe, 2003). The authors recognise the potential limitations of the sample, however, due to the exploratory nature of this practitioner research, the self-selected sample offered a useful representation of the perceptions and experiences of the cohort (Cousin, 2009).

The reading list analysis was based on a checklist of criteria informed by key themes emerging from the literature and previous research studies (for example, Stokes and Martin, 2008; Winter and Dismore, 2010). These included the language and terminology used to annotate the reading list, such as "Core" or "Suggested" reading. The checklist also looked at the structure of the reading lists, if they were divided by topic, resource type or session. A sample of 12 module 
reading lists from the Foundation Degrees in Health and Education were selected and anonymised. These were then analysed against the checklist by both researchers independently, before the results were compared and agreed.

The information from the literature review and reading list analysis was used to inform the questions and prompts for the student focus groups and semi-structured staff interviews. The researchers conducted four focus groups with students from Education and Health, one focus group with each of the Level 4 and each of the Level 5 students. The Level 4 students had experienced the annotated reading lists and the Level 5 students had used non-annotated reading lists. A third party was asked to conduct the focus groups in order to avoid students being intimidated by answering questions from someone they knew (Cousin, 2009). During the focus groups students were asked to review the sample reading lists, commenting on what they liked and disliked and they were also asked for their views on the use of labels identified from the reading list analysis.

The semi-structured style of the interviews with academic staff provided the flexibility needed to explore their feelings and personal experience of reading lists (Davies, 2007; Denscombe, 2003). Eight interviews were conducted with academic staff experienced with teaching FD students in both subjects. The first six interviews were at the beginning of the research process, exploring their thoughts and use of reading lists. The final two interviews were each conducted with a small number of academic tutors together, in order to encourage discussion and ascertain their thoughts on the sample reading lists, these followed similar prompts to the student focus groups.

These methods were selected to allow the authors to identify key themes and issues around the use of reading lists (Cousin, 2009). The reading list analysis enabled the authors to ascertain current practices in reading list development within Education and Health and identify examples of good practice and areas for development. The quantitative data was enriched by the interviews and focus groups, which generated in-depth discussion in relation to staff and students' perceptions and experiences of finding information from reading lists (Robson, 2011; Bell, 2010).

The focus groups and interviews were audio recorded and fully transcribed by an external service. The transcripts from the students and staff were analysed using thematic analysis to determine if there were similar ideas and experiences amongst the staff and student groups, identifying "data-driven" themes (Braun and Clarke, 2006, 15; Robson, 2011). The thematic analysis allowed the researchers to review the data sets separately and compare the themes they identified in a thematic map (Maunder et al., 2010; Robson, 2011).

The researchers began the thematic analysis by tagging the transcripts with key language from the interviewees. These were then grouped under core categories (Cousin, 2009; Braun and Clarke, 2006; Boulton and Hammersley, 1996). This method of qualitative data analysis is interpretative and comprises an inherently subjective process. Therefore, the authors reviewed the transcripts separately and 
then compared their findings (Bell, 2010; Cousin, 2009). The themes identified through the qualitative research methods were then triangulated with the quantitative data from the reading list analysis to evaluate the value of reading lists to support FD students' development of IL skills (Robson, 2011).

\section{Data analysis: results}

The findings of this research can be applied to the wider HE sector, because students at all levels have to explore the information landscape of a new subject area. The core principles of information literacy (to scope, gather, present and evaluate information) can be demonstrated within a reading list (SCONUL, 2011). Signposts within an annotated reading list, to different resources at various levels, can help to teach information skills and to build the confidence of students as they read and learn about the topic. Academics can use this research as an indication of some of the key issues experienced by students in exploring a new subject area. They can therefore consider what they can do to improve their reading lists to help students develop some core information skills. The results of the research are presented in four parts: student reality; academic staff reality; reading list reality; discussion and recommendations.

\section{$5.1 \quad$ Student reality}

The discursive and interactive nature of the focus group method enabled an exploration of possible factors affecting students' confidence in finding and using information (Cousin, 2009; Craig and Corrall, 2007; Zoellner et al., 2008). Students saw reading lists as a starting point to direct them to literature, but they also found them overwhelming. Both subject groups at Levels 4 and 5 saw reading lists as a starting point. They based their choice of reading on availability and staff recommendations. Level 5 students were more likely to use journal articles and showed more discernment according to authors' writing style. All focus groups were consistent in discussing the need for a common standard and layout for reading lists. Students wanted academic staff to clarify how they expected students to use reading lists.

The students were asked to review 12 reading lists and rank them from best to worst. These are the same lists analysed for the research. Students were unanimous in rating " $\mathrm{A}$ " as the best reading list because of its clear layout, annotations and student recommendations. The Education focus groups both listed "H" as the worst because it had inaccurate references and a "squashed" layout. However, the Health students rated "I" as the worst because it had too much information, "an endless list of books" which left the students with the feeling that they did not know where to start. The students wanted more direction to their reading lists with subheadings and signposting to specific chapters.

The researchers identified labels used on the reading lists to establish what the students thought they meant. These labels were: core; essential; recommended; useful; indicative and suggested. There was a lot of discussion around the hierarchy of the words with some confusion as to their meanings. Both Health groups ranked them in the same order, starting with "core" then "essential". 
However, the education groups put "essential" first as a word that would encourage them to "race to the Library". "Useful" was low on the list with "indicative" causing confusion and uncertainty as to its meaning amongst all focus groups, one group describing it as a "non-word". Table 1 compares the student and staff understanding of the meanings of labels commonly used in reading lists. They are ordered by number, 1-5, with 1 being the most important: resources with that label would be prioritised. Both staff and students saw "essential" as the most important resources. Staff said they only used this word for professional standards, whereas students saw these resources as "life or death". There was agreement that the next label in importance was "core", but many staff did not use the label, or only used it for a couple of sources that underpinned the module. "Indicative" was rated poorly by both staff and students. Although staff saw the label as important, students did not understand its meaning. Table 1 highlights the gap between the student and staff interpretation of the labels.

\subsection{Staff reality}

The initial staff interviews looked at how academics viewed reading lists. The second round of staff interviews reviewed the reading lists and labels. Staff agreed that the purpose of a reading list was a starting point and to offer guidance to good quality reading. However, one member of staff described a danger that students may not look for anything else; they may see the list as complete. Academic staff discussed how they expected students to select and locate information from the reading list, therefore highlighting how they can be used to develop IL skills. They expected students to read around and to explore the topic. One academic explained that students were expected to look through the texts, using the indexes and references to navigate through a book.

Few of the academics interviewed gave guidance to their students about how they were expected to use reading lists. They may give session specific readings or recommend readings in lecture PowerPoint presentations. Some see the session specific readings as a way of "training" students to read regularly. Few gave significant amounts of advice. The interviews asked academics about the structure and format of their reading lists as well as their experience with reading lists.

When asked if they included a range of resources academics showed a preference for books although some did include sources such as websites and journal articles.

Initially it's much easier to pick up a book and read it, and bear in mind, our students we just want them to start reading because a lot of them are almost afraid of reading. So, actually something that somebody can actually pick up and hold in their hand and read is probably less daunting.

[Interview 5] 


\begin{tabular}{|c|c|c|c|c|}
\hline Label & & $\begin{array}{c}\text { Student } \\
\text { understanding }\end{array}$ & & Staff understanding \\
\hline CORE & 2 & $\begin{array}{l}\text { Start here } \\
\text { Most relevant } \\
\text { Whole module } \\
\text { Good foundation } \\
\text { Generic } \\
\text { Not exhaustive }\end{array}$ & 2 & $\begin{array}{l}\text { Didn't use } \\
\text { One or two texts the module is } \\
\text { based around } \\
\text { Theoretical perspective that } \\
\text { underpins the module }\end{array}$ \\
\hline ESSENTIAL & 1 & $\begin{array}{l}\text { Most important } \\
\text { Life or death } \\
\text { Race to the library } \\
\text { Highly recommended }\end{array}$ & 1 & $\begin{array}{l}\text { Top } \\
\text { Use for professional standards } \\
\quad \text { (e.g. NMC) }\end{array}$ \\
\hline RECOMMENDED & 3 & $\begin{array}{l}\text { Need to read } \\
\text { Others found it useful } \\
\text { From past student } \\
\quad \text { perspective } \\
\text { Suggested }\end{array}$ & $=4$ & $\begin{array}{l}\text { Interchangeable with suggested } \\
\text { Surely everything on your } \\
\text { reading list should be } \\
\text { recommended? }\end{array}$ \\
\hline USEFUL & 4 & $\begin{array}{l}\text { Worth reading } \\
\text { Might help } \\
\text { Suggested }\end{array}$ & 3 & $\begin{array}{l}\text { Wider reading } \\
\text { Peripheral topics } \\
\text { Further things to explore if } \\
\text { interested }\end{array}$ \\
\hline INDICATIVE & $\mathbf{X}$ & $\begin{array}{l}\text { Not first choice } \\
\text { Have a look } \\
\text { Unsure of meaning } \\
\text { 'non-word' } \\
\text { Don't like the word } \\
\text { Doesn't mean } \\
\text { anything } \\
\text { Wouldn't grab you } \\
\text { Handy }\end{array}$ & 5 & $\begin{array}{l}\text { Important but students may not } \\
\text { understand } \\
\text { Don't use } \\
\text { About module content, not } \\
\text { reading materials } \\
\text { Students don't understand it }\end{array}$ \\
\hline SUGGESTED & & & $=4$ & $\begin{array}{l}\text { Tutor's personal } \\
\text { recommendation } \\
\text { Broader perspective } \\
\text { Recommended }\end{array}$ \\
\hline
\end{tabular}

Table 1: student and staff understandings of reading list labels.

Academics illustrated their awareness of some of the barriers the FD students face 
"trying to think about their sort of self-esteem and confidence as well when I'm looking at the reading list", although the academic went on to explain that they had not read everything on their reading list. Some of those interviewed admitted that they were not good at keeping reading lists up to date and only looked at updating them once a year - demonstrating that they had become static lists, updated with module handbooks as required, rather than as a pedagogical tool. Academics did not expect student feedback on reading lists "students tend to take on face value what you give them and they're quite passive in that" [Interview 5]. They do not appear to challenge students to "evaluate" the books on reading lists. They use assignments to see what students are reading, which sometimes include irrelevant and out-of-date sources [Interview 6].

From the interviews it was clear that academics saw reading lists as an introduction to subject specific readings, which they may subdivide into sessional readings to "train" students to read regularly. However, they did not identify a reading list as useful in helping students to understand the scope of the information landscape or to help them gather further information for their course (SCONUL, 2011).

\subsection{Reading list reality}

Fourteen reading lists were analysed using criteria developed from the reading (Stokes and Martin, 2006). The checklist looked at the types and number of sources, the use of labels and the accuracy of the information. The average number of items on the reading lists was 34.5 items, the most was 59 and the fewest 17. On average books made up $74 \%$ of the lists. Table 2 illustrates the dominance of books on the reading lists, which predisposes the students to rely on books as information sources. Only six of the reading lists had any journals listed on them. The researchers found that $13 \%$ of the books were available as eBooks, but only $3 \%$ were labeled as such (Table 3 ). Access to these resources online is important for these students as they do not always have the time to get to campus to access resources. The analysis demonstrated that $11 \%$ of the books on the reading lists were out of date, with later editions available. $31 \%$ of the items on the reading lists contained some incorrect information, such as poor references, typographic errors or spelling mistakes. Therefore the reading lists did not provide a good model of academic referencing, nor did they aid students in accessing current and relevant resources (SCONUL, 2011).

\begin{tabular}{|l|l|l|}
\hline Types of resources & Number & Percentage \\
\hline \hline Books & $\mathbf{2 8 5}$ & $74 \%$ \\
\hline Journals & $\mathbf{2 3}$ & $6 \%$ \\
\hline Websites & $\mathbf{5 4}$ & $14 \%$ \\
\hline Electronic resources & $\mathbf{1 0}$ & $3 \%$ \\
\hline
\end{tabular}

Table 2: Types of resources on reading lists. 


\begin{tabular}{|l|l|l|}
\hline Accuracy & Number & Percentage \\
\hline Referenced according to Harvard UN & $\mathbf{6 7}$ & $17 \%$ \\
\hline Incorrect / missing information & $\mathbf{9 6}$ & $25 \%$ \\
\hline Typos / spelling / formatting / punctuation & $\mathbf{2 6}$ & $7 \%$ \\
\hline Out of date (Later edition available) & $\mathbf{4 1}$ & $11 \%$ \\
\hline Total no. of items with inaccurate information & $\mathbf{1 2 2}$ & $32 \%$ \\
\hline Items available as eBooks (but not labelled) & $\mathbf{5 0}$ & $13 \%$ \\
\hline Items labelled and available as eBooks & $\mathbf{1 1}$ & $3 \%$ \\
\hline
\end{tabular}

\section{Table 3: Accuracy of reading lists.}

\subsection{Discussion}

The collation and comparison of student and staff transcripts illustrate a gap between the students and staff. From the interviews it was clear that academics were aware of a mismatch between student and staff expectations of a reading list and how to use it.

I think many of them, God bless them, think that reading the book means just that. Reading the whole book, chapter by chapter, by chapter.

[Interview 7]

This illustrates how current reading lists may not help students to evaluate the resources and reading lists they use (SCONUL, 2011).

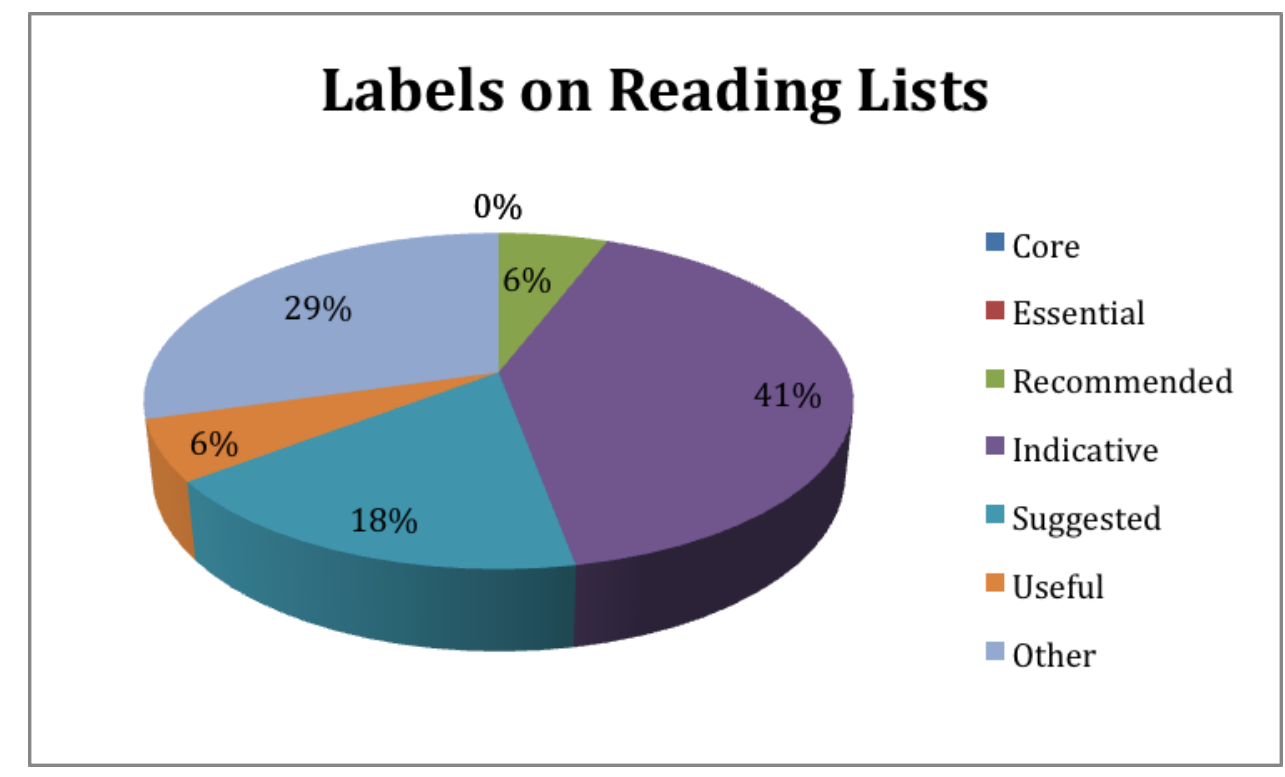

Figure 2: Illustration of how many reading lists use labels.

None of the reading lists used the terminology "core" or "essential", however these were the two labels for which both students and staff shared an agreed meaning. "Indicative", which was the least understood by students, was used on 
$41 \%$ of reading lists. The labels rated poorly by students were the ones used most often on the reading lists analysed (Figure 2).

Students may not have developed advanced reading strategies when they start at University, but they expect the resources that they are expected to read to be relevant to their topic.

I once found a book that was on the reading list ... but it actually had nothing to do with the topic. And I found myself reading it thinking it must do but it was ... I think it was a bit of a mistake.

This student demonstrates that they were evaluating the relevance of the source for their need (SCONUL, 2011).

Therefore, academic staff were aware of students' lack of academic skills, but were perhaps not conscious of some of the anomalies that appear in their reading lists and how this affects the students. Despite these divergent viewpoints the thematic analysis of student focus groups and staff interviews highlighted these key themes:

The research objectives are:

- Starting point and signpost.

- Modeling and developing an academic toolkit.

- Scaffolding (spoon-feeding).

Both students and staff saw reading lists as "a starting point":

I think it's to give the students a starting point; it gives them some good quality readings that you hope that they would use to get them going.

[Interview 1]

This is a common perception of the purpose of a reading list at HE level, the basis of independent study. However, if academics are wary of giving "too much", the question is, how much is enough and when do you cross the line into giving the students everything?

We don't want students to feel that's all they have to look at and that's probably the danger of a reading list.

[Interview 5]

The academics interviewed were clearly trying to strike a balance between too little information and spoon-feeding. One first year student viewed the reading list as a "security blanket" which supports the idea that students might rely too 
heavily on reading lists to the detriment of their academic development. Fundamentally, there is a massive gap between where the students have come from academically and what is expected of them at HE.

It is a massive journey for them. I think we need to help them at every opportunity with things like good reading lists and good resources that they can get every time they want them.

[Interview 3]

When looked at in this way, reading lists can become pedagogical tools to support students' development of IL skills and they can scaffold students:

I think we also need to look at reading lists as being something that is progressive and related to academic level of study... I don't think we take into account that students at Level 4 when they are coming into their first year of study need a greater degree of guidance and support in terms of understanding this thing called a reading list and if it is suitably and well-thought through that this can change and develop and evolve year on year, so that the student isn't going to need the level of support and guidance in Year 3, you would hope, that they required in Year 1

[Interview 7]

The uneasy balance between scaffolding and spoon-feeding is illustrated by this student:

Maybe they could put examples of good chapters to read or is that just making it too easy for us?

Both staff and students are clearly aware of how reading lists could be mismanaged to limit student information skills development, by over- or underdeveloping the reading lists. Whilst the academics interviewed showed appreciation of student difficulties, few of the analysed reading lists provided additional support and direction.

Students appreciate guidance and direction. The interviews encouraged the academics to reflect on their comfort within the academic arena and how that is a very different experience to how the students feel - how they have to boost student confidence and self-esteem: "I think many of them have a very low level of confidence and self-esteem” [Interview 7]. By modeling good academic practice (such as accurate referencing) a reading list can scaffold students' skills development. They did not discuss the contradiction of marking students' references, but not checking their own reading lists.

It does make me chuckle when I get the odd reading list and I look and I think typo, spelling mistake, error and then we get penalised 
However, mistakes cause confusion and frustration - when students are marked on referencing but academics are not. "I've found mistakes at one point, yeah, quite a few times actually" [Year 2]. The fundamental issue, why are students required to adhere to a specific standard if the academics are not? How does this encourage students to pay attention to academic standards? HE has progressed beyond the traditional adage "do as I say, not as I do". In this instance, the reading list failed to demonstrate how to use and manage information effectively (SCONUL, 2011).

The student focus groups demonstrated that they were using reading lists to develop information skills:

if you're stuck [on] what words to use in these search engines ... you look at the reading list and it speaks a word 'manipulative' and you think well I'll try that.

[Year 2]

They used keywords to find and locate information and follow reference trails:

if you find a core text and you do some work from it you'll find a reference in the book that leads you on.

[Year 1]

Therefore, even without direct guidance students were using the reading list to develop information skills. Specifically, these students were articulating how they identify, scope, plan and gather information by using reading lists to identify keywords, and then follow reference trails (SCONUL, 2011). This research project encouraged the academics to reflect on their own practice. The academics recognised that they could be more explicit with students about their expectations of how students use reading lists. The quotation below clearly illustrates that reflection on their current action:

I'm not sure there is a common understanding of this thing called reading lists. I'm not sure students know what it is that it's designed for, I'm not sure we share it with them, and the other part of it is I'm not sure that we share explicitly with students why they are reading, why this thing called reading as an activity can help them ...

[Interview 7]

We almost think that it's cheating if we tell students, if we share with students our background knowledge of something that is a bit off the wall... we would share this with one of our colleagues if we found out. Why are we thinking that somehow it's not right to share that with students, that they should find their own way and get muddled. 
This process gave the academics an opportunity to reflect on their own practice and look at reading lists from the students' point of view. Some began to see that they may be putting additional barriers in front of students. This is exemplified on the staff review of the reading lists:

I have to say I have never seen such a long reading list in all my life, it's forty odd books... It's amazingly long. I would actually look at this and think 'oh goodness I won't bother'. It's huge ... I wouldn't know which ones to start with. It's just too big.

[Interview 7]

The students agreed with this view, labeling it as one of the worst reading lists because it was "an endless list of books". However, although there is a shared appreciation of what constitutes good and bad reading lists, there is a mismatch when academics write and update them.

I think we need to think about them more. I think we do them because we have to and we should, but I don't necessarily think that we see it from the students' point of view. We see the compilation of a reading list as a lecturer's responsibility to read widely, to recommend or whatever term you want to use, but I don't think we actually look at it from the students' viewpoint.

[Interview 7]

This is illustrated when students and staff gave their interpretation of the meanings of the labels used on reading lists. Fundamentally, reading lists are being delivered to students as they have been, for years, but little thought or time has been given to why they exists or what more they could be.

\section{$5.5 \quad$ Recommendations}

The research demonstrates that there are problems with current readings lists, which can be static and inaccurate, but the students interviewed demonstrated that they were using them to access and retrieve resources. The project also highlighted the possibilities of reading lists, how much they could be used to teach students information skills, if they were used more effectively:

- If academics annotated reading lists, sharing their knowledge and experience, it would encourage students to develop academic skills, such as reading strategies.

- Explanations of topics or resources would help students, early on in their HE career to understand the variety of sources out there and how to begin to compare the different viewpoints.

- Signposting to students how to access resources, such as online eBooks, helps 
students to become confident with the information landscape.

- Modelling academic standards with referencing helps students to gain familiarity and confidence within the HE environment, and aids them in locating information.

Bringing together clear, accurate, annotated reading lists will support students with a scaffold to help them develop the Information Skills necessary to reach their academic potential.

Therefore, annotated and scaffolding reading lists would help students identify the range of information available, identify what best suits their needs and evaluate those resources (SCONUL, 2011).

\section{Conclusion}

Reading lists are under-used in their role as a pedagogical tool to develop information literacy skills. The annotated reading lists analysed in the research were the most popular with the student focus groups. They were recognised for their clarity and approachability. It provided encouragement, specifically with its student recommendations. This helps to support students developing confidence in finding, using and evaluating information, if they can see that other students found specific resources useful and informative. The labels used on reading lists illustrate the difference between student and staff experience and expectations of reading list. Table 1 demonstrates the understandable confidence of academics in using labels for reading lists and highlights the students' misconceptions of some of the terms. These misunderstandings could easily be clarified by staff if they annotated their reading lists and shared their expectations with students either verbally or on the list itself.

The reading lists can help to bridge the gap between staff and students to support them to develop information skills. A well-structured reading list demonstrates how to evaluate and present information and acts as a communication of staff expectations.

The results of this study demonstrate how students are already using reading lists as a means to scope and gather information in their subject area. However, more can be done to provide a consistent exemplar model of good information skills practice. The research has highlighted the potential of reading lists, which has not yet been realised. 


\section{References}

Bamber, J. and Tett, L. (2000) Transforming the learning experiences of nontraditional students: a perspective from higher education, Studies in Continuing Education, 22(1), 57-75.

Bell, J. (2010) Doing your research project: a guide for first-time researchers in education, health and social science. $5^{\text {th }}$ ed. Maidenhead: Open University Press.

Boulton, D. and Hammersley, M. (1996). Analysis of unstructured data. In: Sapsford, R. and Jupp, V. (eds.) Data collection and analysis. London: SAGE. 282-297.

Bowl, M. (2001) Experiencing the barriers: non-traditional students entering higher education, Research Papers in Education, 16(2), 141-60.

Bowl, M. (2003) Non-traditional entrants to higher education: "They talk about people like me”. Stoke on Trent: Trentham.

Braun, V. and Clarke, V. (2006) Using thematic analysis in psychology, Qualitative Research in Psychology, 3(2), 77-101.

Brewerton, G. (2014) Implications of student and lecturer qualitative views on reading lists: a case study at Loughborough University, UK. New Review of Academic Librarianship. 20, 78-90.

Bryman, A. (2012) Social Research Methods. $4^{\text {th }}$ ed. Oxford: Oxford University Press.

Cavendish, C. (2013) The Cavendish review: an independent review into healthcare assistants and support workers in the NHS and social care settings. Department of Health [online]. URL:

https://www.gov.uk/government/publications/review-of-healthcare-assistants-andsupport-workers-in-nhs-and-social-care [accessed 16.12.13].

Chipperfield, S. R. (2013) Self-preservation and the individualisation of risk in university-based foundation course students, Journal of Further and Higher Education, 37(5), 623-642.

Cohen, L., Manion, L., Morrison, K. and Bell, R. (2013) Research Methods in Education. Abington: Routledge.

Collins, K.M.T. and Veal, R.E. (2004) Off-campus adult learners' levels of library anxiety as a predictor of attitudes toward the internet, Library \& Information Science Research, 26(1), 5-14.

Cousin, G. (2009) Researching learning in Higher Education: an introduction to contemporary methods and approaches. London: Routledge. 
Craig, A. and Corrall, S. (2007) Making a difference? Measuring the impact of an information literacy programme for pre-registration nursing students in the UK, Health Libraries Group, 24(2), 118-127.

Davies, M.B. (2007) Doing a successful research project: using quantitative or qualitative methods. Basingstoke: Palgrave Macmillan.

Denscombe, M. (2003). The good research guide for small-scale social research projects. $2^{\text {nd }}$ ed. Maidenhead: Open University Press.

Gray, D. E. (2009) Doing research in the real world. London: Sage.

Fenge, L.A. (2011) "A second chance at learning but it's not quite higher education": experience of a foundation degree, Journal of Further and Higher Education, 35(3), 375-390.

Harvey, L. (2009) Review of research literature focussed on Foundation degrees, FDF [online]. URL: http://www.heacademy.ac.uk/assets/documents/fdf/Reviewof-research-literature-focussed-on-foundation-degrees.pdf [Accessed 16.12.13].

Herrera, H., Broan, D. and Portlock, J. (2014) Foundation degree learning: an educational journey of personal development. Journal of Further and Higher Education, [online]. URL:

http://www.tandfonline.com/doi/abs/10.1080/0309877X.2013.869562 [Accessed 8.11.14].

House of Commons Public Accounts Committee (2009) Widening participation in higher education. Fourth Report of Session 2008-09 [online]. London: The Stationery Office. URL:

http://www.publications.parliament.uk/pa/cm200809/cmselect/cmpubacc/226/978 0215526557.pdf [Accessed 10.5.11].

James, K. (2002) Report and literature review into the role of self-esteem as a barrier to learning as an outcome. NIACE and Department for Education and Skills [online]. URL: http://www.niace.org.uk/Research/HDE/Documents/selfesteem.pdf [Accessed 17.11.14].

Laing, C., Chao, K. M. And Robinson, A. (2005) Managing the expectations of non-traditional students: a process of negotiation, Journal of Further and Higher Education, 29(2), 169-179.

Lumsden, E., McBryde-Wilding, H. And Rose, H. (2010) Collaborative practice in enhancing the first year student experience in higher education. Enhancing the Learner Experience in Higher Education [online], 2(1), 12-24. URL:

http://journals.northampton.ac.uk/index/php/elehe/index [Accessed 13.12.10].

Maher, J.M. and Mitchell, J. (2010) I'm not sure what to do! Learning experiences in the humanities and social sciences, Issues in Educational Research, 20(2), 137148. 
Martin, L. and Stokes, P. (2006) Reading lists under the spotlight: Cinderella or superstar? SCONUL Focus, 37 (Spring), 33-36.

Maunder, R. E., Gingham, J. and Rogers, Jenine (2010) Transition in Higher Education: exploring the experiences of first and second year psychology undergraduate students, The psychology of education review, 34(1), 50-54.

McDevitt, N. (2006) Unmasking the imposter phenomenon. McGill Reporter [online]. 38(17). URL: http://www.mcgill.ca/reporter/38/17/zorn/ [Accessed 8.6.12].

McKenzie, J. (1999) Scaffolding for Success, The Educational Education Journal, 9(4). [online] URL: http://fno.org/dec99/scaffold.html [Accessed 5.5.11].

Miller, B. (1999) An integrated taxonomy of student reading and learning development, Journal of Further and Higher Education, 23(3), 309-316.

Moon, J. (2005) Coming from Behind: an investigation of learning issues in the process of widening participation in higher education. [Abstract from the final report].

Morris, T.M. (2009) An investigation into the provision and impact of foundation degrees for teaching assistants [online]. Ph.D. Thesis, University of Birmingham. URL: http://etheses.bham.ac.uk/633/ [Accessed 8.6.12].

Penketh, C. and Goddard, G. (2008) Students in transition: mature women students moving from Foundation Degree to Honours level 6, Research in PostCompulsory Education, 13(3), 315-327.

Piscioneri, M. and Hlavac, J. (2013) The minimalist reading model: rethinking reading lists in arts and education subjects, Arts and Humanities Higher Education, 12(4), 424-445.

Pratt, G. (2008) Implementing the assistant practitioner foundation degrees, British Journal of Healthcare Assistants, 2(1), 37-41.

Robson, C. (2011) Real world research: a resource for users of social research methods in applied settings. $3^{\text {rd }}$ ed. Chichester: John Wiley and Sons Ltd.

Russell, M. (2009) Towards more confident learners: the use of academic mentors with foundation degree students, Research in Post-Compulsory Education, 14(1), 57-74.

SCONUL (2011) The SCONUL Seven Pillars of Information Literacy. Core Model for Higher Education. SCONUL.

Smith, H. (2008) Spoon-feeding: or how I learned to stop worrying and love the mess, Teaching in Higher Education, 13(6), 715-718. 
Stark, S. and Warne, T. (1999) 'Connecting' the Distance: relational issues for participants in a distance learning programme, Journal of Further and Higher Education, 23(3), 391-402.

Stokes, P. and Martin, L. (2008) Reading lists: a study of tutor and student perceptions, expectations and realities, Studies in Higher Education, 33(2), 113125.

Thomson, L., Mason, C. and Thomas, L. (2003/2004) Reading lists - How do you eat yours? Learning and teaching projects. Centre for Learning and Teaching. University of Wolverhampton. URL: www.wlv.ac.uk/celt. [Accessed 16.12.13].

Thurgate, C., MacGregor, J. and Brett, H. (2007) The lived experience: delivering a foundation degree in health and social care, Journal of Further and Higher Education, 31(3), 215-223.

University of Northampton (2013) Widening Participation University of Northampton [online]. URL: http://www.northampton.ac.uk/staff/equality-anddiversity/widening-participation [Accessed 16.12.13].

Van Der Stuyf, R. (2002) Scaffolding as a teaching strategy, Adolescent Learning and Development. Fall, 2-13.

Winter, J. and Dismore, H. (2010) Investigating the experiences of foundation degree students progressing to an honours degree: an integrated approach, Journal of Further and Higher Education, 34(2), 253-270.

Zoellner, K., Samson, S. and Hines, S. (2008) Continuing assessment of library instruction to undergraduates: a general education course survey research project, College \& Research Libraries, 69(4), 370-383.

\section{The Occasion}

This research was funded by the 2011 LIRG Research Award.

\section{Open access and copyright}

Library and Information Research is an open access journal. A freely available copy of this paper may be downloaded from the journal's website:

http://www.lirgjournal.org.uk.

Copyright and associated moral rights in works published in Library and Information Research are retained by the author(s) but this paper may be used freely, with proper attribution, in educational and other non-commercial settings. 